\title{
LUZAZUL: Metodologia de criação e gerenciamento de hipermídia para inclusão cultural e formação de público a serviço da AZULEJARIA NO PATRIMÔNIO ARQUITETÔNICO Pelotas / RS
}

LUZAZUL: creation methodology and management of hypermedia for cultural inclusion and public education in the service of TILES IN THE ARCHITECTURAL HERITAGE Pelotas / RS

\author{
- João Fernando Igansi Nunes \\ Brasil \\ fernandoigansi@gmail.com
}

\begin{abstract}
LUZAZUL - Light Blue project is interdisciplinary, curricular action as documentation and conceptual production strategy for theory and practice, focused on heritage as cultural inclusion vector, public training and development of integrated movable manners. It is based especially on hypermedia resource whose central object is the inventory of the TILE IN ARCHITECTURAL HERITAGE Pelotas - RS, electronically duplicated and made available on mobile, wireless devices. Exploring the conditions of free software platforms, this initiative invests in building method for the development, agency and updating publishable data into digital language.
\end{abstract}

Keywords: Tile, Hypermedia, Communication, Inclusion, Education

\section{Introdução}

A condição da sociedade assistida pelo computador é foco central desta proposta, bem como para a compreensão dos processos de agenciamentos humanos em interação com a máquina, nos seus respectivos níveis de acesso e atualização. A automatização do processo de reconhecimento de padrões, nesse projeto, perpassa o exemplo do grupo SOFTWARE STUDIES, as experiências do projeto Letter Spirit de Gary E McGraw Jr. e os desenvolvimentos dos projetos em Interfaces Dinâmicas do Laboratório Paragraphe - Universidade Paris VIII, Paris - Fr. Através da experiência do projeto Memória Gráfica de Pelotas: um século de design, explorarse-à as condições técnicas e o paradigma conceitual das comunicações permeadas pelos seus duplos virtuais, com aplicação em escolas e grupos de pessoas com deficiência. A construção de um aplicativo em hipermídia capaz de analisar e sintetizar os padrões da AZULEJARIA NO PATRIMÔNIO ARQUITETÔNICO para seu respectivo acesso e interação converge para a questão fundamental da Comunicação e do Patrimônio virtualizado.

Inserido na linha temática Comunicação, dentro do subtema Cidades Digitais [alíneas c) desenvolvimento de aplicativos para dispositivos móveis, com foco em governo eletrônico e softwares livres e d) apoio à ampliação do uso de tecnologias da informação e da comunicação nas redes locais que se refere a educação, essa proposta corrobora o pressuposto de que a 'cidade digital" expõe e documenta o processo histórico como um arquivo da memória coletiva. Observase que a tipologia e a arquitetura dos museus virtuais realiza aproximações com a configuração e traçados das cidades, incorporando o contexto urbano como acervo. Semelhante a um percurso museal, o projeto LUZAZUL permite opções de ordenação das informações, oferecendo ao usuário contemplação, reflexão e aprendizado sobre as recorrências e desenvolvimento de seu patrimônio de azulejaria. Considerase que a virtualização neste projeto tem a meta de relacionar a obra com o espaço, a gestão com os projetos de comunicação e fornecer caminhos para a percepção, valorizando paisagens, lugares e memórias como fontes de conhecimento em dialógico sistema interdisciplinar.

Aproximaremos a virtualidade patrimonial à compreensão do que se instaurou chamar de 'museu difuso". A denominação museu difuso é proveniente da Itália e, no Brasil, geralmente confunde-se com o que se considera como museu de território, ecomuseu ou museu ao ar livre, já que estes se aproximam no sentido de possuírem um sistema de gestão que utiliza os habitantes em conexão com os visitantes. A idéia de ecomuseu foi formulada na década de 1970, na França, e assim denominado por Hugues de Varine.

Acrescenta ao museu tradicional a experiência do espaço e do tempo, ou seja, as variações de diversos lugares num 
mesmo tempo e de um mesmo lugar em diversos tempos. $\mathrm{Na}$ concepção do museu clássico ou tradicional a ação museológica se dá utilizando as relações espaciais e de comunicação entre o edifício, a coleção e o público. Já no museu difuso esta acontece considerando o território, o patrimônio e a comunidade (YUNES, 2012).

O museu difuso é uma ação coletiva em que o conhecimento do especialista é confrontado continuamente com a percepção dos moradores e visitantes. Considera que o patrimônio cultural territorial documenta aspectos da identidade local, sem a necessidade de concentrar objetos em espaços contenedores. Ao contrário, baseia-se na idéia de que lugares e monumentos, em seus ambientes originais, possuem a capacidade de melhor contar a sua própria história.

Assim, o museu difuso mostra ao sujeito onde e como os processos históricos se materializaram em vestígios que incidem na paisagem, ou seja, geram produtos reconhecidos pela qualidade documental. Por consequência, o espaço museográfico é considerado como espaço de comunicação, onde a informação incorpora-se à exposição e ao uso do lugar musealizado.

A interpretação da cidade como museu difuso associase e tem apoio na Legislação Brasileira ao entendimento dos direitos difusos. Estes são considerados como direitos "transindividuais", superando então o âmbito do indivíduo e caracterizando-se por sua indivisibilidade. Entende-se que a satisfação do direito deve dirigir-se ao coletivo, exemplificado em ações como a de respirar ar puro, a qualidade de vida e o acesso ao patrimônio cultural, ou seja, definidas como um bem comum que, no caso de perda, não permite ser valorado e ter seu resgate calculado isoladamente.

A cidade vista sob a gestão do museu difuso assume estes aspectos de relevância social para sua comunidade considerando que ela é repositório e testemunho das relações invisíveis e indivisíveis da produção anônima de um grupo organizado e é sedimentada em um território no tempo.

Assim acontece a aproximação da leitura da cidade, transfaceada pelo seu duplo digital, com o conceito de museu difuso. O museu virtual mostra, em hipertenso, onde e como processos históricos se materializaram. O espaço museográfico, nesse sentido, é considerado como espaço de comunicação, onde a informação incorpora-se à exposição e ao uso do lugar.

Conforme observa Pesavento (2008, p.4), "podemos ter sido induzidos, educados e ensinados a identificar lugares de uma cidade, partilhando das mesmas referências de sentido, em um processo de vivência do imaginário urbano coletivo". Assim reforça-se aqui a idéia de exibição, da expografia, do projeto de um curador ou gestor que seleciona e organiza as informações da vida urbana. Trata-se de realizar a leitura do espaço urbano como o lugar de experimentações e construções sociais que se efetivam no tempo e definem territórios e acervos sedimentados como um arquivo passível de investigações e revelações.

Considerando que o projeto LUZAZUL tem a meta de relacionar a obra com o espaço, contemplando a formação de público aos bens patrimoniais, a gestão e os projetos de comunicação e percepção atuam de forma eficaz como elementos estruturadores e facilitadores dos espaços urbanos, valorizando lugares e memórias como fontes de conhecimento.

O estudo tem como base a descoberta e evidência de exemplares que permitam a relação entre configuração espacial, acervo e planejamento das exposições dos lugares urbanos virtualizados pela potência dos códigos algorítmicos. O Design Computacional, tratado na lógica da cibercultura, operados por numa linguagem executável, transcende os limites estáticos do projeto fixado em suporte rígido, por conseguinte, se distancia dos processos de transmissão de dados e da projeção perspectivista das representações.

Um objeto computacional, nesse sentido, pode ser real ou abstrato. Os objetos computacionais possuem informações (contém dados) e desempenham ações (estado de execução das regras de funcionamento).

Pode-se compreender o próprio "evento", rotina de processamento de dados, como um "objeto" computacional, aquilo que se produz, se desenvolve e se atualiza na linguagem dos softwares. Resultado da escrita do código, o desenho acontece na sua ação e nela permanece enquanto há execução. O objeto existe, dessa maneira, na condição de uma linguagem executável, construído por uma biblioteca de classes préexistentes e compartilháveis, desde que escritas em alguma linguagem de programação. Os códigos de execução são linguagens que habitam e se desenvolvem como máquinas heterogêneas, não são "locomotivas" que transportam dados mas dados que agem, funcionam em outros dados. ampliandose pela carga de "velocidade" em que se agitam os fluxos de banda, elétrons e memória. Na perspectiva de Galloway "O código é uma linguagem, mas uma espécie muito especial de linguagem. O código é a única linguagem que é executável."

Há um "pensamento computacional" gerado nesse estatuto de linguagem que é lógica de processamento e produção de meta-signos. Ele constitui-se nas relações entre o funcionamento técnico e o seu respectivo conteúdo tecnológico de comunicação processado. Situado nas estruturas de linguagens algorítmicas. Esse "pensamento computacional" evolui de um estado diagramático do imaginário técnico de MacLuhan para um imaginário tecnológico emergente das máquinas abstratas de Chomski, conforme Felix Guattari em L'Anti-Edipe descreve suas maquinas desejantes e autopoeticas.

A problemática das técnicas está na dependência das questões das máquinas, não o inverso. Máquina e técnica mudam de "papéis" segundo o enfoque e o ponto de vista tomado. A fala é uma máquina da linguagem, a linguagem se faz máquina para os discursos e, o discursos são máquinas para as idéias que, consequentemente, são máquinas da fala. Conceitos que estão além das conhecidas máquinas técnicas, como "um todo em seus avatares técnicos, sociais, semióticos, axiológicos", com poderes singulares de enunciação e agenciamento. 
Nesta esteira, os avanços tecnológicos forjaram novas aplicações e novos corpos para o Design, assim como para o desenvolvimento da Cibernética, fundada por Norbert Wiener (1948) que formaliza a noção de feedback e retroação, com respectivas implicações no domínio da engenharia e dos controles dos sistemas: sejam eles da informática, da biologia, da filosofia ou das organizações das sociedades.

Antes o salto sobre a página para construir os espaços, agora a repetição da ação sobre a barra de espaço do teclado e o enter para trocas de linhas explicitam as especificidades dos editores de textos, como os hipertextos de WikiWiki, uma escrita "que não sulca a superfície, mas viabiliza mecanismos de criação coletiva e anônima" (Beiguelman. 2003:38), funcionam como 'e-palimpsestos', como o RIOT de Mark Napier.

Lessig sugeriu que 'Código é lei', mas se o código é lei é lei como um 'administrador de infrações'. Lógicas formais são inerentemente incompletas e indiscernívelmente existem máquinas que quebram essas lógicas, os programas são defeituosos, os projetos são abandonados e os sistemas hackeados. E, como o filósofo Alfred North Whitehead demonstrou, os seres humanos são literalmente infectados por abstrações. Isso não é algo ruim, porque como o vírus que produziu variedades de tulipas de uma beleza rara, a infecção pode ser algo muito criativo.

Neste caso, as considerações de Lev Manovich sobre sua teoria de uma metamídia fazem-se referências que clarificam a compreensão das inúmeras mídias que o designer utiliza para um tipo de projeto que desenvolve. Editores de textos, editores de imagens, plugins e diversos aportes de sistemas são necessários para, por exemplo, colocar uma simples homepage no ambiente das redes de hyperlinks da WWW. No exemplo de Jeremy Blake.

O design é, e tem sido, o resultado da interação entre estética e ciência, ambas no sentido cultural histórico da sociedade que se recria nas invenções e técnicas desenvolvidas para seu funcionamento. Um certo estado variável e complementar entre magia e racionalidade; entre imaginação e realidade.

Nessa perspectiva, sistematizou-se o projeto a partir das investigações da tríade Interface, Interação e Agenciamento. Considera-se as redes de hipermídia um processo computacional, como ferramenta e meio de estratégia para a apresentação e acesso que a azulejaria detêm, desde seus elementos compositivos de forma e estrutura, bem como sua localização, histórico e demais especificidades.

Toda nova tecnologia gera novos métodos de criação e, por conseguinte, novas criaturas. Para tanto, todo processo criativo demanda de análise e ação, e se o termo empregado é "processo", pressupõe-se um continuo. A ação nesse caso é dada pela função programada. É o que está por traz da ferramenta que age sobre a configuração do objeto e todo seu contexto de composição e espaço e, análise pelo reconhecimento desse todo.

Como metacriação, metamidia, metalinguagem. A questão não é representar o existente, é criar o "não possível", não como exclusivamente "novo" mas como modelado, gestado e evolutivo, como duplo do seu contexto.

\section{Procedimentos Metodológicos}

Neste projeto, as ações previstas para atingir os objetivos, bem como alcançar as metas, organizam-se em quatro ações que se desenvolverão concomitantes ao longo de 12 meses e objetivam gerar produtos e processos para a efetivação do aplicativo hipermídia e seu uso com os grupos parceiros.

\section{São ações gerais do projeto:}

Reuniões administrativas e pedagógicas: pressupõe uma reunião geral, com pauta definida ao longo da semana, focada para a apresentação e debate das dificuldades dos grupos, informações gerais, monitoramento dos recursos e apresentação da avaliação de cada grupo dos seus resultados. São reuniões que também integram os parceiros. Ocuparão 4 horas mensais em turno e dia específicos.

Oficinas de estudo para desenvolvimento do aplicativo.

Grupos deestudo com os professores das escolas envolvidas para desenvolvimento do aplicativo e do uso do aplicativo: a função desta reunião mensal é aproximar o grupo alvo do grupo de trabalho e, em especial, desenvolver o aplicativo com a participação dos agentes educacionais de modo que possam orientar questões de conteúdo e melhor usabilidade.

Reuniões de avaliação: nestas, os grupos de trabalho apresentarão mensalmente os resultados, bem como a avaliação do processo. Desse modo, todos estarão a par dos produtos que estarão em curso pelos colegas.

O projeto LUZAZUL - Metodologia de criação e gerenciamento de hipermídia para inclusão cultural e formação de público a serviço da AZULEJARIA NO PATRIMÔNIO ARQUITETÔNICO Pelotas / RS utiliza como referência o mapeamento visual dos estilos da azulejaria advindos dos Países Europeus. Coordenado e desenvolvido pelo prof. Dr. Gilberto Sarkis Yunes, o referido projeto encontra-se protocolado no CAPES/CNPq, com resultados de publicação em YUNES, G. Sarkis. Azulejos Antigos na Arquitetura Tradicional de Pelotas e do Sul do Estado. In: Maria Amélia Bulhões Garcia. (Org.). Artes Plásticas no Rio Grande do Sul. Pesquisas Recentes.. Porto Alegre: UFRGS, 1995, v. , p. 85-102. AZULEJARIA NO PATRIMÔNIO ARQUITETÔNICO DO RIO GRANDE DO SUL foi desenvolvido com o apoio da FAPERGS, do CNPq e do Programa Especial de Treinamento - PET/CAPES, 1995. O processamento necessário para a atualização desse projeto em hipermídia envolverão ainda o desenvolvimento de três sistemas distintos e complementares, que são: o rastreamento do banco de imagens para a leitura e conseqüente leitura de padrões gráficos; um sistema de atualização e acesso dos dados; sistema de interação e sistema de navegação.

Cada sistema de codificação e decodificação, terá seu específico processo de análise e síntese dos padrões verificados nos estilos gráficos dessa azulejaria, por exemplo: sistema de 
busca a partir da relações entre diferenças e repetições nos padrões existentes.

Explorar-se-á ainda o uso dos banco de dados compatível às mídias móveis. Nessa perspectiva existe a necessidade de se utilizar tecnologia de sistemas distribuídos: agentes móveis (implementados em Java) ou objetos distribuídos compartilhados, por exemplo do HiperGPS. O formato das Redes Sociais implementará e operacionalizará as avaliações dos envolvidos perante seu publico de acesso. Em síntese, a organização dos trabalhos será:

Consulta das referencias técnicas e conceituais;

Reuniões com o grupo SOFTWARE STUDIES DO BRASIL;

Visita ao Centro de Documentação sobre Azulejos no Uruguai;

Visita ao Centro de Documentação sobre Azulejos na Argentina;

Reuniões com o grupo SOFTWARE STUDIES da UCSD/

San Diego, California;

Visita ao Museu do Azulejo em Lisboa, Portugal;

WorkShops;

Teleconferências.

\section{Materiais e Infra-estrutura}

Computadores, plataforma Apple, de Mesa MB420BZ/A iMac 24' LCD/3.06GHz/4GB/1TB/SuperDrive//NVIDIA GeForce GT 130-512MB/AP/BT) no mínimo, com opção de Upgrade para $32 \mathrm{~Gb}$ de memória, prevendo a implementação de modelos formais que permitam a transcrição virtual da AZULEJARIA NO PATRIMÔNIO ARQUITETÔNICO Pelotas / RS;

Telefones celulares de baixo custo;

Máquina fotográfica digital Nikon;

Impressora 3D CubePro para produção de objetos com resolução de 70 mícrons por camada feitos nylon ou de plástico ABS ou PLA.

Para o desenvolvimento desta arquitetura de informações será utilizado o paradigma de programação orientada a objetos, a partir das tecnologias OpenSource e de plataformas lógicas Java e Processing.

\section{Avaliação}

São instrumentos de avaliação: os formulários entregues ao público alvo para serem preenchidos sob orientação dos professores colaboradores. Os instrumentos de avaliação serão aplicados ao final de cada etapa.

1a etapa: avaliação feita pelos consultores de todos os itens do projeto. Aplica-se a todos os membros do projeto e pressupõe avaliação mensal.

2a etapa: avaliação do rendimento dos membros da equipes feita pela equipe geral através de seminário interno sobre todos os itens do projeto concluído. Recurso a ser aplicado no 6o. e 12o. mês do projeto.

3a etapa: avaliação feita pelo público alvo e público em geral através de instrumentos específicos (entrevistas, fichas de avaliação de exposição, coleta de dados através dos parceiros).

4a etapa: avaliação do uso da hipermídia pelos estudantes.

O projeto que formulou o objeto desta proposta iniciou em 1997 como um levantamento da azulejaria histórica das cidades gaúchas que contivessem exemplares destes bens integrados em edificações protegidas ou consideradas históricas. Durante dois anos um grupo de professores coordenados pelo arquiteto e professor do então Instituto de Letras e Artes da UFPel, Gilberto Sarkis Yunes, orientou alunos de graduação e especialização para o registro e documentação deste acervo em 11 cidades do Estado (Pelotas, Porto Alegre, Rio Grande, Bagé, Jaguarão, Santa Vitória do Palmar, Rio Pardo, Livramento, Alegrete, Arroio Grande e Piratini) foram identificados e registrados mais de 100 exemplares diversos, sendo 24 destes em Pelotas. Estava dado um importante passo para a proteção deste acervo. Outras iniciativas posteriores somaram-se a esta documentação.

O projeto busca: propor soluções que viabilizem a informação de fácil percepção para diferentes públicos partindo do princípio que a valorização dos vestígios memoriais depende, sobretudo, do acesso ao conhecimento e que as novas tecnologias são ferramentas de grande impacto para o acesso à informação. Assim, entende-se que é possível e desejável harmonizar as soluções inovadoras que as novas técnicas oferecem para promover um ambiente que possa contribuir para potencializar o repertório estético, sensível e expressivo de jovens estudantes, pessoas com deficiência e um amplo e heterogêneo público; oportunizar na formação de alunos dos cursos de graduação da UFPel consciência sobre responsabilidade de seu campo profissional com o desenvolvimento de ações voltadas para a melhoria social, para o uso do conhecimento a favor da sociedade, para a capacitação da consciência sobre o patrimônio e os bens culturais, como agentes partícipes da identidade dos grupos e da memória social. O segundo fundamento da proposta é o sistema de compartilhamento de informação e otimização da produção científica, pedagógica e de assistência à comunidade.

No contexto da cidade é importante salientar que a azulejaria histórica remanescente encontra-se diversos edifícios da cidade, muitos inventarias e localizados nas ZPPCs, contribuindo para a caracterização das áreas de especial interesse do ambiente cultural que, conforme consta no Plano Diretor da cidade, definem-se por ser "aquelas que apresentam patrimônio de peculiar natureza cultural e histórica, que deva ser preservado, a fim de evitar perda, perecimento, deterioração ou desaparecimento das características, das substâncias ou das ambiências culturais e históricas que lhe determinem a especialidade, visando a recuperação dos marcos representativos da memória da cidade e dos aspectos culturais de sua população" (Art, 64, p.19). Mais adiante, na mesma Lei, lê-se que nestas: "devem ser mantidas as características tipológicas e formais, fachadas públicas e volumetria da arquitetura tradicional existente e integrante do Inventário do Patrimônio Histórico e Cultural de Pelotas 
em Lei Municipal."(idem, Art.148, p.52). Na paisagem da cidade, de casas térreas, muitas construídas nas primeiras décadas do Século XX, as fachadas já foram suprimidas destes ladrilhos, que ainda subsistem no interior das casas. Preservá-los, pressupõe propor uma parceria com a comunidade. Entendese que possa ser esta a relação que fará com que a comunidade incorpore o valor deste patrimônio. Trata-se, portanto de apostar na possibilidade de que o trabalho resulte no desejo de políticas públicas voltadas para estes acervos frágeis e que se ressentem pelo pouco reconhecimento. Aposta-se que a hipermídia gera um espaço de educação informal, fortemente ancorado em princípios memoriais e pode, consequentemente, contribuir com a função extrovertora do conhecimento acadêmico. Destaca-se a parceria com o poder público municipal e a possibilidade de melhoria das ações de educação de jovens estudantes para o patrimônio.

A hipótese aqui levantada como discurso encontra reforço no argumento apresentado por Richard Rogers (2008, p.18) de que "as próprias cidades podem representar uma grande ferramenta, um laboratório vivo para a educação". Portanto, por analogia, entende-se que a exposição do acervo que documenta a cidade proporciona a observação e a reflexão in loco da produção humana no espaço e no tempo real. Considerada no seu aspecto informacional e de organização como um texto a ser lido, conforme Rolnik (1992, p.28) "a cidade, por excelência, produz e contem documentos, ordens, inventários" cuja "arquitetura urbana também cumpre este papel de escrita, de texto que se lê da mesma maneira que se lê um processo, um relato de um viajante".

Os conceitos de documento, memória e patrimônio numa escala urbana passam a adquirir mais clareza quando se pensa em bens difusos ou bens coletivos. Se a ideia de patrimônio está diretamente ligada à atribuição de valor e de herança, o que se transfere de uma geração para outra, de um tempo para outro tempo, conforme observa Chagas (1994), pode-se afirmar que seu papel como resíduo de um tempo é mais do que matéria, é a representação do conhecimento e a incorporação de significado. Neste sentido, quando se pensa na cidade, considera-se que ela própria é um arquivo da sua memória por meio dos vestígios materiais sobreviventes do passado. Além dos edifícios, os aparelhos urbanos e os bens móveis integrados constituem-se em documento urbano, como azulejaria em coleção, associa-se a aquilo que ensina, que é suporte de informação.

Assim vista, a cidade passa a ser composta por diversos lugares, que possuem cargas simbólicas diferentes que, como conjuntos ou objetos seriados, retomam a definição da cidadearquivo, apresentando-se geralmente com o aspecto de cidadecolagem. Desta maneira, as sucessivas construções vinculamse no tempo por meio do espaço, consagrando-o como lugar. Formadores da paisagem urbana, fontes de informações presentes, configuram-se potencialmente como um livro aberto para o conhecimento e subsidio de ações futuras.

A ação LUZAZUL é ação curricular do cursos de Design Gráfico, Design Digital, Arquitetura, Computação e
Conservação e Restauro. Sua instância de projeto que trata a azularia como um objeto físico, de referências visuais/gráficas e estilísticas, tratado e duplicado digitalmente, disponibilizado e agenciado em dispositivos móveis (com potência de realidade aumentada) gerando acervo museal virtualizado para sistemática reprodução em impressão 3D.

Com referências no Grupo de Pesquisa SOFTWARE STUDIES DO BRASIL, veiculado ao Grupo de pesquisa SOFTWARE STUDIES, o presente projeto intitulado LUZAZUL é instrumento metodológico para criação e gerenciamento de hipermídia a partir de softwares livres. Caracteriza-se como estímulo às investigações que se iniciam no Colegiado de Design - CA - UFPel, sob o pressuposto de que meios específicos de escritas demandam processos específicos de leituras.

Em concordância, como indicam seus autores, o Software Studies é um novo campo de pesquisa intelectual que está começando a surgir. O primeiro livro que tem essa temática como título foi publicado pelo MIT Press em Junho de 2008 (Matthew Fuller, Org., Software Studies: A Lexicon). O Projeto Software Studies tem a intenção de ser a peça chave para estabelecer esse campo de pesquisa na área acadêmica. Atualmente ocupa um grande espaço nas discussões do FILE - Festival Internacioinal de Linguagens Eletronicas / SP. O Grupo de Software Studies está sediado na UCSD, sob coordenação do Prof. Dr. Lev Manovich. No Brasil, o grupo pertence ao FILE Labo (Laboratório do Festival Internacional de Linguagens Eletrônicas) e é coordenado pelo Prof. Dr. Cicero Silva, pesquisador do CRCA na UCSD e, a partir desse projeto, implementa-se o Grupo no Rio Grande do Sul, com sede no Colegiado de Design do Centro de Artes - UFPel, sob a coordenação do Prof. Dr. João Fernando Igansi Nunes. Cientistas sociais, filósofos, críticos culturais, artistas e designers, téoricos da mídia e das novas mídias parecem atualmente compreender muitos dos aspectos da revolução da Tecnologia da Informação (TI), criando um número expressivo de novas disciplinas, tais como cibercultura, Internet Studies, Teoria das Novas Mídias e Cultura Digital.

Sua natureza acadêmica encontra lastro na compreensão inequívoca sobre a relevância do tema para a qualificação de alunos dos cursos de Design Gráfico, Design Digital, Museologia e Arquitetura, no qual expressa a máquina computacional como meio, mais que ferramente de trabalho; que suporta e direciona os campos e as áreas dos saberes - a partir da linguagem computacional - e que tem recebido pouca ou nenhuma atenção direta. Registra-se, neste sentido, que o software, principalmente o de plataforma livre, é geralmente invisível para a grande maioria dos acadêmicos e/ou profissionais da cultura contemporânea: interessados diretos em tecnologia da informação e em seus efeitos a memória e ao patrimônio. Certamente, ao limitar as discussões críticas às noções de 'ciber,' 'digital', 'novas mídias' ou 'Internet', estaremos conduzindo ao perigo por lidar somente com os efeitos e não com as causas. Corre-se o risco, nestes casos, de ficar-se observando somente os resultados que aparecem na tela do computador em vez de analisar os programas e as 
culturas sociais que produzem esses efeitos.

LUZ, como imagem fantasmática, como signo de duplicação digital, virtualiza o AZULejo e o disponibiliza, compartilhando e instaurando possível política às ações de conservação. Metodologia de criação e gerenciamento de hipermídia a serviço da AZULEJARIA NO PATRIMÔNIO ARQUITETÔNICO DO RIO GRANDE DO SUL - UFPEL, compreende o efeito na experiência do processo.

A sociedade informacional, compreendida pelo estatuto das interfaces culturais e interativas, está para além da Galaxia de Gutemberg. Na emergência de um novo tipo de Tele-Visão, prenunciada por Paul Virilio, conduz para a necessidade de uma cidadania construída no espaço das redes multimidiáticas, capazes de interações tateis, auditivas, verbais e visuais simultaneamente, Suas identidade múltiplas, caracterizadas por comunidades em vulnerabilidade, fortalecem-se pela instrumentalização aos usos extensivos das tecnologias, conduzem-se pela potência do acesso e, assim, fortalecem e corroboram a expansão dos grupos envolvidos, gerando formação qualificada aos valores patrimoniais e de agenciamentos simbólicos, fundamentais para inclusão e prática ativa de cidadania.

\section{Referências}

Balasubramanian, V. (1994). State of the Art Review on Hypermedia Issues And Applications. Graduate School of Management, Rutgers University, Newark, New Jersey. IN: http://wwwis.win.tue.nl/2L690/opdracht/chapter0.html

Bica, F.; Silveira, R.; Viccari, R. (1998). Educação a distância: do paradigma de tutores inteligentes a uma arquitetura multiagente. $\mathrm{V}$ Congresso Internacional de Educação a distância. ABED, São Paulo.

Bra, P. de; Calvi, L. Aha (1998): a generic adaptative hypermedia system. Proocedings. II Workshop on Adaptative hypertext and hypermedia . Pittsburg: USA. Pag. 20-24.

Bradshaw, J. M. (1997). An introduction to software agents. IN BRADSHAW, J. M. Ed. Software agents. MIT Press. Massachusetts.

Cauquelin, A.(2007). A Invenção da Paisagem. São Paulo: Martins Fontes.

Chaiben, H. (1997). Hipermídia na educação. Universidade Federal do Paraná, IN: www.cce.ufpr.br/ hamilton/hed/hed. htm

Chagas, M. (1994). Em busca do documento perdido: a problemática da construção teórica na área da documentação. Cadernos de Museologia, n. 2, p.29-47.

Eberspächer, H.; Kaestner, C. (1998). A Geração de uma ferramenta de autoria para sistemas tutores inteligentes hipermídia' 3rd Symposium Investigation and Development of Educational Software. Évora: Portugal, September.
Goldberg, M. W.; Salari, S.; Swoboda, P. (1996). World Wide Web-Course Tool: an environment for building WWW-based courses. Fifth Inernational World Wide Web Conference. Paris: France.

Halasz, F.G. (1998). Reflections on notecards: seven issues for the next generation of hypermedia systems. Communications of the ACM. July. Vol. 31 No. 7. Pag. 836-851.

Henriques, M. A. A. (1998). Uma Proposta para o Processamento Massivamente Paralelo na Internet. Relatório técnico. Faculdade de Engenharia Elétrica e de Computação. Campinas.

Huyssen, Andreas.(1994). Escapando da Amnesia. O museu como cultura de massa. Revista do Patrimonio Historico e Artistico Nacional. No. 23. Rio de Janeiro: IPHAN.

Pesavento, S. J. (2008). História, memória e centralidade urbana. Revista Mosaico, v.1, n.1, p.3-12.

Minsky, M. (1981), A framework for representing knowledge. Mind design, pag. 95-128.

Morgado, L. (1998). O lugar do hipertexto na aprendizagem: alguns princípios para a sua concepção. IN http://www. moderna.com.br/escola/prof/art22.htm\#hip Setembro.

Oliveira, P.C. (1997). Sistemas baseados em agentes móveis: uma abordagem alternativa para o desenvolvimento de sistemas distribuídos. Dissertação de tese. Faculdade de Engenharia Elétrica e de Computação - UNICAMP. Campinas. PimentelL, M. G. C.; Santos, J.B. Jr; Mattos, R.P. de (1998). Tools for authoring and presenting structured teaching material in the WWW.Webnet'98 (World Conference on the WWW, Internet, \& Intranet), Orlando, USA, November.

Rodrigues, R.; Moraes, M.; Pimentel, N.; Veras, D. (1998) Introdução à educação a distância. Programa de capacitação a distância. Laboratório de ensino a distância, UFSC.

Rolnik, R. (1992). História urbana: História na cidade? In: Cidade \& História / Ana Fernandes e Marco Aurélio A. de F. Gomes (Org.). Salvador: UFBA / Faculdade de Arquitetura. Mestrado em Arquitetura e Urbanismo; ANPUR.

Shank, R.C. (1991). Where's the AI? AI Magazine.

Silveira, M.; Arruda, L. (1998). Desenvolvimento de um Sistema Multimídia para a Autoria e Apresentação de Cursos de Controle. 3rd Symposium Investigation and Development of Educational Software. Évora: Portugal.

Turoff; Murray; RAO; USHA; HILTZ. (1991). Collaborative Hypertext in Computer Mediated Communications, Proceedings. Twenty-Fourth Annual Hawaii International Conference on System Sciences.

Yunes, G. S.(2012). Uma ilha de paisagens culturais e espaços museográficos. In: Patrimônio cultural e cidade contemporânea /Alicia Norma González de Castells, Letícia Nardi (organizadoras). Florianópolis: Editora UFSC. 